\title{
Prey switching by Acartia clausi: experimental evidence and implications of intraguild predation assessed by a model
}

\author{
Ingrid Gismervik ${ }^{1, *}$, Tom Andersen ${ }^{2}$ \\ 'Section of Marine Zoology and Chemistry, University of Oslo, PO Box 1064 Blindern, N-0316 Oslo, Norway \\ ${ }^{2}$ Section of Marine Botany, University of Oslo, PO Box 1069 Blindern, N-0316 Oslo, Norway
}

\begin{abstract}
Switching between algal (Thalassiosira weissflogii) and ciliate (Strobilidium undinum) food by the marine copepod Acartia clausi was investigated in the laboratory by short incubation experiments with ${ }^{14} \mathrm{C}$-labeled prey. A. clausi displayed a Holling type 3 functional response (which differed significantly from a type 2 response, $p<0.05$ ) for ciliates when there was a constant abundance of algae present, and likewise for algae when there was a constant abundance of ciliates present. The results were implemented in a mathematical model to investigate the effect of different functional responses on a simple food web comprised of nutrient, algae, ciliates and copepods. In the model, ciliates and copepods competed for resources (algae) and ciliates were also prey for copepods. This blend of predation and competition among copepods and ciliates corresponds to intraguild predation as defined by Polis \& Holt (1992; Trends Ecol Evol 7:151-154). Stable solutions with all state variables present were found over a range of nutrient concentrations when the copepods displayed type 3 functional responses. On the contrary, when copepods displayed type 2 responses, such stable solutions were only found at very low input nutrient concentrations. Coexistence of ciliates and copepods further required that ciliates had a lower threshold prey concentration for positive net growth than copepods.
\end{abstract}

KEY WORDS: Prey switching · Acartia clausi Ciliates - Copepods - Algae · Model · Intraguild predation $\cdot$ Stability $\cdot$ Coexistence

\section{INTRODUCTION}

The feeding response displayed by a predator in relation to the density of prey (functional response) is important for the stability of prey-predator relationships. Holling (1959) argued that an S-shaped functional response (termed type 3 ) has the potential to regulate prey density, in contrast to rectilinear (termed type 1) or curvilinear (termed type 2) functional responses. This relates to the fact that the per capita prey mortality inflicted by a predator increases with prey concentration when the predator displays a type 3 response. This response is also termed a switching response, following the definition of Murdoch (1969): 'As a prey become relatively more abundant, switching occurs if the relative amount which that species

·E-mail: ingrid.gismervik@bio.uio.no forms of the predator's diet increases disproportionately in comparison with the expected amount'. Copepods have commonly been recognized as grazers which have non-increasing clearance rates with increasing prey concentrations (e.g. Mullin et al. 1975, Kleppel 1993). This response, however, implies that the copepods display non-variable selectivity or no selectivity at all.

While functional responses are often measured in 1 prey situations in the laboratory, predators in situ have a choice between several prey types. Field studies suggest that copepods are opportunistic feeders, concentrating their feeding efforts on the most abundant prey (Wilson 1973, Richman et al. 1977, Poulet 1978). This suggests that clearance rates should increase as the concentration of a specific prey item increases, and that the per capita prey mortality for the specific prey will increase when concentrations are enhanced. 
A type 3 response in grazers may result from different factors like reduced handling time of prey (Holling 1959), concentration of search activity in profitable micro habitats (Royama 1970) or optimizing of energy gain (Lehman 1976). It may also be a result of switching between 2 prey species, where the feeding effort on the most abundant prey is enhanced due to shifts in 'search image' (Tinbergen 1960) or shifts in feeding behaviour (Marten 1973). Several copepod species have turned out to be omnivores (e.g. Stoecker \& Capuzzo 1990), switching between a secondary and a tertiary trophic position in the food web. There is evidence that some of these copepods have at least 2 different feeding strategies; suspension feeding on small, relatively immobile prey and ambush feeding on larger motile prey (Gauld 1966, Wilson 1973, Landry 1981, Koehl 1984, Jonsson \& Tiselius 1990, Tiselius \& Jonsson 1990, Chow-Fraser \& Sprules 1992). Copepods with different feeding strategies can be distinguished by morphological characteristics (Schnack 1982, Landry \& Fagerness 1988) as well as different swimming patterns (Lowndes 1935, Green 1988, Tiselius \& Jonsson 1990). By filming Acartia tonsa, both Jonsson \& Tiselius (1990) and Kiørboe et al. (1996) have shown that the time allocated to ambush and suspension feeding changes with the composition of food.

The type 3 functional response has several interesting properties (Murdoch \& Oaten 1975). Prey species will experience refuge or at least reduced mortality risk below some threshold prey concentration. However, as prey concentration increases, the predator will increase its clearance rate, and may thus control prey abundance. Given that the response works at realistic prey abundances this may hinder one prey species in monopolizing resources and ensure coexistence of several species.

We wanted to investigate whether Acartia clausi (Giesbrecht), a potential switching copepod, displays type 3 functional responses for algae and/or ciliates when presented with a mixture of diatoms and oligotrich ciliates. Our experimental results were incorporated in a mathematical model to investigate which effect copepods with different functional responses have on a simplistic 4 component food web.

\section{MATERIAL AND METHODS}

Experiments. Two laboratory experiments were performed in December 1995. Ciliates were collected from the Oslofjord (Norway) and fed a monoculture of Nephroselmis pyriformis (Prasinophyceae). One species was isolated and identified as Strobilidium undinum (Martin \& Montagnes 1993) by the protargol staining technique (Montagnes 1993). Four days prior to the first experiment 2 Thalassiosira weissflogii cultures were inoculated, whereof one was supplied with inorganic ${ }^{14} \mathrm{C}\left(0.1 \mu \mathrm{Ci} \mathrm{ml}{ }^{-1}\right)$. A batch of $S$. undinum were fed ${ }^{14} \mathrm{C}$-labeled $N$. pyriformis daily for $6 \mathrm{~d}$ prior to the second experiment. Ciliates and algae for microscopical enumeration were fixed with $2 \%$ and $1 \% \mathrm{v} / \mathrm{v}$ acid Lugol's iodine, respectively. The calanoid copepod Acartia clausi was collected from the Oslofjord 5 to $7 \mathrm{~d}$ before the experiments (surface temperature of $5^{\circ} \mathrm{C}$ and salinity of $30 \%$ ) and acclimated to an experimental temperature of $-11^{\circ} \mathrm{C}$ and salinity of $25 \%$. The copepods were fed $T$. weissflogii during acclimatization, and also $S$. undinum the day prior to the experiment. They were kept in darkness both prior to and during the experiments.

Approximately 20 female Acartia clausi were acclimated for $2 \mathrm{~h}$ in $500 \mathrm{ml}$ glass beakers with ciliates and algae added to final concentrations before an inoculum of labeled Thalassiosira weissflogii (Expt 1) or labeled Strobilidium undinum (Expt 2) was added (Table 1). Only ciliate cultures where the food algae Nephroselmis pyriformis was grazed down were used. The ciliates were nevertheless healthy and swimming, and no change in their condition was observed during the incubation. After $20 \mathrm{~min}$ the copepods were gently poured onto a small sieve, quickly rinsed by filtered sea water, and anaesthetized with MS 222. The copepods were immediately counted and placed in scintillation vials. Tissue solubiliser $\left(200 \mu \mathrm{l}\right.$, Soluene $\left.{ }^{\mathrm{IM}}\right)$ was added, and the samples were left over night before scintillant was added. The samples were left for another night and then counted in a scintillation counter. Four different volumes of the labeled $T$. weissflogii and the labeled $S$. undinum cultures were filtered onto GF/F filters after the experiments, and the activity per cell was calculated from regression curves. The regression curves for total DPM (disintegrations per minute) as a function of volume of labeled $S$. undinum culture filtered were linear. Hence, there seemed to be no losses of ciliates due

Table 1. Thalassiosira weissflogii and Strobilidium undinum. Concentrations in experimental beakers. Three replicates for each treatment

\begin{tabular}{|lrrrrrr|}
\hline & \multicolumn{7}{c}{ Concentration (cells ml ${ }^{-1}$ ) } \\
\hline Expt 1 & & & & & & \\
$T$ weissflogii & 220 & 317 & 510 & 702 & 1084 & 1463 \\
S. undinum & 13 & 13 & 13 & 13 & 13 & 13 \\
$\begin{array}{l}\text { Labelled } \\
\quad I \text { weissflogii }\end{array}$ & 123 & 123 & 123 & 123 & 123 & 123 \\
Expt 2 & & & & & & \\
$T$. weissflogii & 585 & 585 & 585 & 585 & 585 & 585 \\
$\begin{array}{l}\text { S. undinum } \\
\text { Labelled } \\
\quad \text { S. undinum }\end{array}$ & 3.4 & 6.6 & 11.8 & 16.7 & 21.8 & 31.7 \\
\hline
\end{tabular}


to the forcing of a higher amount of water through the filter. We concluded that ciliates were kept on the filter, even if they did break. Thus, we also sampled the ciliate and algae cultures for CN analysis on GF/F filters, and analysis was performed on a Carlo-Erba elemental analyzer.

Model description and incorporation of experimental results. We defined a spatially homogeneous, chemostat-type model (Fig. 1) comprised of 4 state variables; inorganic nutrient $(N)$, algae $(A)$, ciliates $(P)$ and copepods $(Z)$. If we, for simplicity, assume constant stoichiometries in all food web components, we can express all state variables in units of the limiting nutrient (which will usually be nitrogen in a marine system). Both copepods and ciliates feed on the same algae, while copepods are also capable of feeding on ciliates. Although copepods and ciliates have different optimal prey sizes, there exists a range where the 2 groups compete for resources (Gismervik et al. in press). The mass balances corresponding to the flow structure described in Fig. 1 can be represented by the following 4 differential equations (see Tables $2 \& 3$ for symbol definitions and units):

$$
\begin{aligned}
& \mathrm{d} C_{N} / \mathrm{d} t=D\left(C_{N, \text { in }}-C_{N}\right)-\mu_{A} C_{A}+R_{N} \\
& \mathrm{~d} C_{A} / \mathrm{d} t=\left(\mu_{A}-D\right) C_{A}-I_{P} C_{P}-I_{A, Z} C_{Z} \\
& \mathrm{~d} C_{P} / \mathrm{d} t=\left(\mu_{P}-D\right) C_{P}-I_{P, Z} C_{Z} \\
& \mathrm{~d} C_{Z} / \mathrm{d} t=\left(\mu_{Z}-D-m\right) C_{Z}
\end{aligned}
$$

The regeneration term, $R_{N}$ in the mass balance for the inorganic nutrient Eq. (1) will have contributions from both ciliates and copepods. Since all state variables are expressed in nutrient units, the specific nutrient regeneration rate from a given consumer will simply be the difference between ingestion and growth

$$
R_{N}=\left(I_{P}-\mu_{P}\right) C_{P}+f_{R}\left(I_{Z}-\mu_{Z}\right) C_{Z}
$$

Ciliate egesta are assumed to be completely remineralised in the water column, while a fraction $f_{z}$ of copepod egesta is assumed to be lost from the water column as sedimenting fecal pellets. This is accounted for in Eq. (5) by setting the dimensionless parameter $f_{R}=1-\left(1-\varepsilon_{Z}\right) f_{Z}$. Algal specific growth rate, $\mu_{A \text {, is }}$ dependent on external nutrient concentration as described by the common Monod model for nutrient limited growth, with parameters as given in Table 3 :

$$
\mu_{A}=\mu_{A}^{\prime} \frac{C_{N}}{C_{N}^{*}+C_{A}}
$$

The specific growth rates of the consumers, $\mu_{p}$ and $\mu_{z}$, given by the difference between assimilation and maintenance costs:

$$
\begin{aligned}
& \mu_{p}=\varepsilon_{p} I_{P}-r_{p} \\
& \mu_{Z}=\varepsilon_{Z} I_{Z}-r_{Z}
\end{aligned}
$$

Ciliate ingestion rate, $I_{p}$, is assumed to follow a type 2 functional response, with parameters as given in Table 3 :

$$
I_{P}=I_{P}^{\prime} \frac{C_{A}}{C_{A, P}^{\prime}+C_{A}}
$$

The ingestion term of copepods is more complex than that of ciliates. Preying on large moving prey (ciliates) and smaller non-motile prey (algae) is mutually exclusive in the sense that the 2 prey appear to be captured by different feeding mechanisms (see 'Introduction'). Thus copepods should feed preferentially upon the most beneficial prey, and there is evidence that they actually do so. According to our and others' results, some copepods are highly selective for ciliates (e.g. Stoecker \& Sanders 1985, Stoecker \& Egloff 1987, Nejstgaard et al. 1997) which are hypothesized to be nutritionally superior food (Stoecker \& Capuzzo 1990, Sanders \& Wickham 1993).

Fig. 1. Flow diagram for a 4-compartment model comprised of nutrient $(N)$, algae $(A)$, ciliates $(P)$ and copepods $(Z)$. Heavy lines denote intercompartmental flows (unbroken and broken lines are assimilation and regeneration fluxes respectively) while thin lines are boundary flows (sedimentation and water exchange)

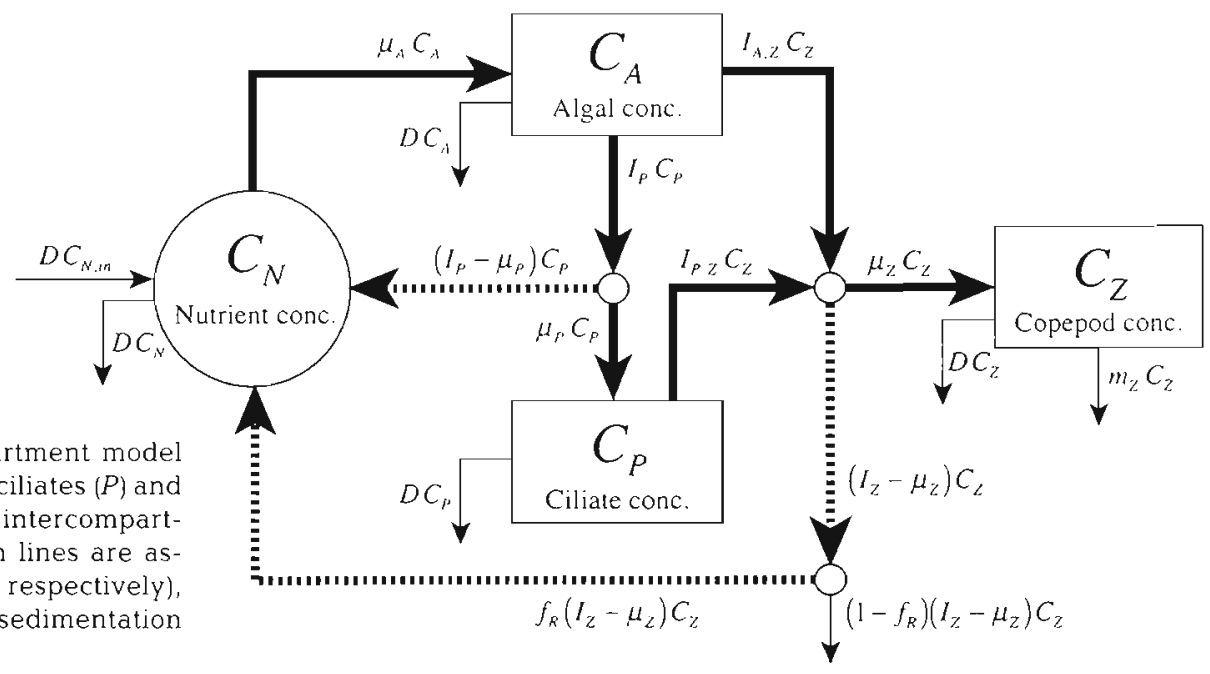


Table 2. Variables and process rates used in model analysis

\begin{tabular}{|llc|}
\hline Parameter & Abbr. & Unit \\
\hline External variable & & \\
Input nutrient concentration & $C_{v_{2},}$ & $\mu \mathrm{MN}$ \\
State variables & & \\
Nutrient concentration & $C_{N}$ & $\mu \mathrm{MN}$ \\
Algal concentration & $C_{A}$ & $\mu \mathrm{MN}$ \\
Ciliate concentration & $C_{P}$ & $\mu \mathrm{MN}$ \\
Copepod concentration & $C_{Z}$ & $\mu \mathrm{MN}$ \\
Process rates & & \\
Algal growth rate & $\mu_{A}$ & $\mathrm{~d}^{-1}$ \\
Ciliate growth rate & $\mu_{P}$ & $\mathrm{~d}^{-1}$ \\
Copepod growth rate & $\mu_{Z}$ & $\mathrm{~d}^{-1}$ \\
Ingestion rate of ciliates on algae & $I_{P}$ & $\mathrm{~d}^{-1}$ \\
Ingestion rate for copepods & $I_{Z}$ & $\mathrm{~d}^{-1}$ \\
Ingestion rate for copepods on algae & $I_{A, Z}$ & $\mathrm{~d}^{-1}$ \\
Ingestion rate for copepods on ciliates & $I_{P, Z}$ & $\mathrm{~d}^{-1}$ \\
Nutrient regeneration from grazers & $R_{N}$ & $\mu \mathrm{M} \mathrm{N} \mathrm{d}^{-1}$ \\
\hline
\end{tabular}

Since a major purpose of this model is to investigate the effects of the copepod functional response on dynamic properties of the food web, we wanted a general representation that is able to cover the basic Holling type 2 and 3 responses as special cases. This can be easily accomplished by introducing a shape parameter $n$ as suggested by Matsuda et al. (1986):

$$
I_{Z}=I_{Z}^{\prime} \frac{\left(C_{A} / C_{A, Z}^{\prime}\right)^{n}+\left(C_{P} / C_{P, Z}^{\prime}\right)^{n}}{1+\left(C_{A} / C_{A, Z}^{\prime}\right)^{n}+\left(C_{P} / C_{P, Z}^{\prime}\right)^{n}}
$$

For the case of $n=1$ and $C_{p}=0$ (i.e. only algal prey present), Eq. (10) will be functionally identical to the Holling type 2 response Eq. (9). If $n=1$ and both algae and ciliates are present (i.e. $C_{A}>0$ and $C_{p}>0$ ), then level curves for constant copepod ingestion rate $\left(I_{Z}\right)$ will be straight lines in the $\left(C_{A}, C_{P}\right)$ plane (illustrated in Fig. 3A in the 'Results' section). This situation corre- sponds to algae and ciliates being perfectly substitutable resources in the terminology of Leon \& Thumpson (1975). By increasing the shape parameter $n$, the level curves of the functional response become more and more convex (as illustrated in Fig. 3C for the case $n=2$ ) - in other words, any combination of the 2 prey species will give less food intake than the same amount of food biomass offered as 1 species alone. It should be noticed that Eq. (10) gives a type 3 response (i.e. a functional response with an inflection point) also in the single-prey situation when $n>1-$ a feature that seems to have support in several feeding studies on Acartia spp. (see 'Discussion'). In the limit, when $n \rightarrow \infty$, Eq. (10) will approach the perfect switching functional response predicted by the theory of optimal foraging for a consumer with 2 mutually exclusive feeding modes (e.g. Stevens \& Krebs 1986).

The grazing losses experienced by each prey type must add up to the total ingestion rate given by Eq. (10), such that if $I_{A, Z}=S_{A} I_{Z}$ and $I_{P, Z}=S_{P} I_{Z}$, then we must have that $S_{A}+S_{P}=1$ (or, equivalently, $S_{P}=1-S_{A}$ ). If we choose

$$
S_{A}=\frac{\left(C_{A} / C_{A . Z}^{\prime}\right)^{n}}{\left(C_{A} / C_{A, Z}^{\prime}\right)^{n}+\left(C_{P} / C_{P . Z}^{\prime}\right)^{n}}
$$

then copepod ingestion rates of algae and ciliates can be written as

$$
\begin{aligned}
& I_{A, Z}=I_{Z}^{\prime} \frac{\left(C_{A} / C_{A, Z}^{\prime}\right)^{n}}{1+\left(C_{A} / C_{A, Z}^{\prime}\right)^{n}+\left(C_{P} / C_{P, Z}^{\prime}\right)^{n}} \\
& I_{P, Z}=I_{Z}^{\prime} \frac{\left(C_{P} / C_{P, Z}^{\prime}\right)^{n}}{1+\left(C_{A} / C_{A, Z}^{\prime}\right)^{n}+\left(C_{P} / C_{P, Z}^{\prime}\right)^{n}}
\end{aligned}
$$

When $n=1$ we will have that consumption is directly

\begin{tabular}{|c|c|c|c|c|}
\hline Parameter & Abbr. & Value & Unit & Source \\
\hline Dilution rate & $D$ & 0.01 & $d^{-1}$ & Arbitrary \\
\hline Max. growth rate for algae & $\mu_{A}^{\prime}$ & 1 & $d^{-1}$ & Eppley et al (1969) \\
\hline Monod parameter for algae & $\mathrm{C}_{\mathrm{N}}^{1}$ & 0.5 & $\mu M N$ & Eppley et al (1969) \\
\hline Max. ingestion for ciliates & $I_{P}^{\prime}$ & 2.5 & $\mathrm{~d}^{-1}$ & Scott $(1985)$ \\
\hline Max ingestion rate for copepods & $I_{Z}^{\prime}$ & 0.5 & $d^{-1}$ & Experiments, see Table 5, 'Results' \\
\hline Incipient lim. algae conc for ciliates & $C_{A D}^{\prime}$ & 0.5 & $\mu \mathrm{MN}$ & Jonsson (1986), recalculated Ks \\
\hline Incipient lim. algae conc. for copepods & $C_{A Z}^{\prime}$ & 0.7 & $\mu M N$ & Experiments, see Table 5 \\
\hline Incipient lım. ciliate conc. for copepods & $C_{p Z}^{\prime \prime}$ & 0.3 & $\mu \mathrm{MN}$ & Experiments, see Table 5 \\
\hline Respiration loss for ciliates & $r_{P}$ & 0.5 & $\mathrm{~d}^{-1}$ & Crawford \& Stoecker (1996) \\
\hline Respiration loss for copepods & $r_{Z}$ & 0.1 & $d^{-1}$ & Kiørboe et al. (1985) \\
\hline Mortality rate for copepods & $m$ & 0.01 & $d^{-1}$ & Carlotti \& Nival (1992) \\
\hline Assimilation efficiency for ciliates & $\varepsilon_{p}$ & 0.8 & & Stoecker (1984) \\
\hline Assimilation efficiency for copepods & $\varepsilon_{z}$ & 0.8 & & Kiørboe et al. (1985) \\
\hline Faecal pellet fraction of non-assimil. food & $f_{z}$ & 0.5 & & Arbitrary \\
\hline Switching shape parameter & $n$ & 1,2 & & Experiments, see Table 5 \\
\hline
\end{tabular}
proportional to relative, effective food concentration (sensu Vanderploeg et al. 1984) — as would be ex-

Table 3. Parameter values used in model analysis 
pected for a consumer with invariant prey selection Level curves for constant prey ingestion rate will then be straight lines (as illustrated in Fig. 3B). If, on the other hand, $n>1$, then Eqs. (12) \& (13) imply that the relative prey consumption will be a power function of relative prey abundance:

$$
\frac{I_{A, Z}}{I_{P, Z}}=\left(\frac{C_{A} / C_{A, Z}^{\prime}}{C_{P} / C_{P, Z}^{\prime}}\right)^{n}
$$

such that the most abundant prey will be consumed disproportionately to its relative abundance (as illustrated in Fig. 3D). This property conforms with the classical definition of a switching predator, according to Oaten \& Murdoch (1975).

Least squares fitting of Eqs. (12) \& (13) to experimental data was performed with the non-linear fit option of the statistics package JMP 3.1 (SAS Institute, Inc.) Model simulations and bifurcation analysis were implemented in the numerical analysis package MATLAB 4.2 (The MathWorks, Inc.). Details on analytical and computational procedures for equilibrium points and local stability analysis are described in Appendix 1. Full MATLAB source code for simulations and bifurcation analysis is available from the authors upon request
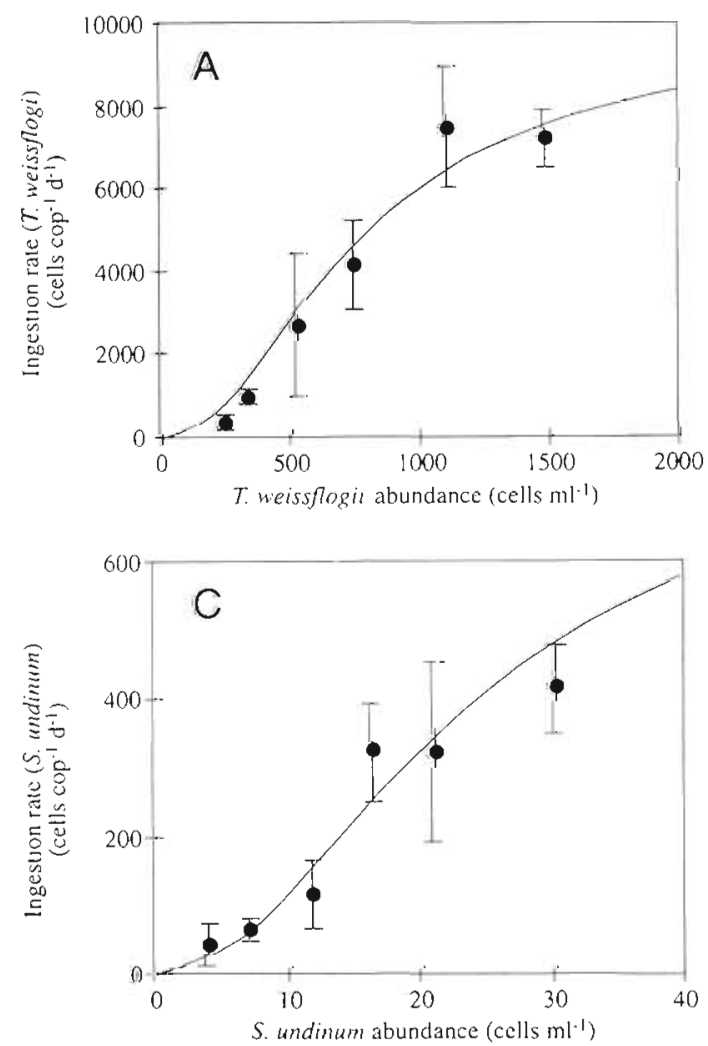

Table 4. Carbon and nitrogen content of experimental organisms

\begin{tabular}{|lcc|}
\hline & $\mu \mathrm{g} \mathrm{C}$ & $\mu \mathrm{g} \mathrm{N}$ \\
\hline Thalassiosira weissflogii & $9.0 \times 10^{-5}$ & $1.6 \times 10^{-5}$ \\
Strobilidium undinum & $1.1 \times 10^{-3}$ & $2.5 \times 10^{-4 \mathrm{~b}}$ \\
Acartia clausi & 3.6 & 0.7 \\
aValues from December of the previous year & \\
(Gismervik 1997a) & \\
'Calculated from C:N ratio of 4.4 (see 'Results') \\
\hline
\end{tabular}

\section{RESULTS}

\section{Experiments and fitted curves}

Carbon and nitrogen content of the experimental organisms are shown in Table 4 . The nitrogen content of the ciliate samples was below the detection limit, thus the nitrogen content was calculated from a $\mathrm{C}: \mathrm{N}$ ratio of 4.4 (Gismervik et al. in press). Ingestion and clearance rates of Acartia clausi on diatoms and ciliates are shown in Fig. 2. The curves that gave the best fit to our data (see below) are included. Below the incipient limiting prey concentration, calculated total ingestion rate for $A$. clausi was highest when a type 2 compared to a
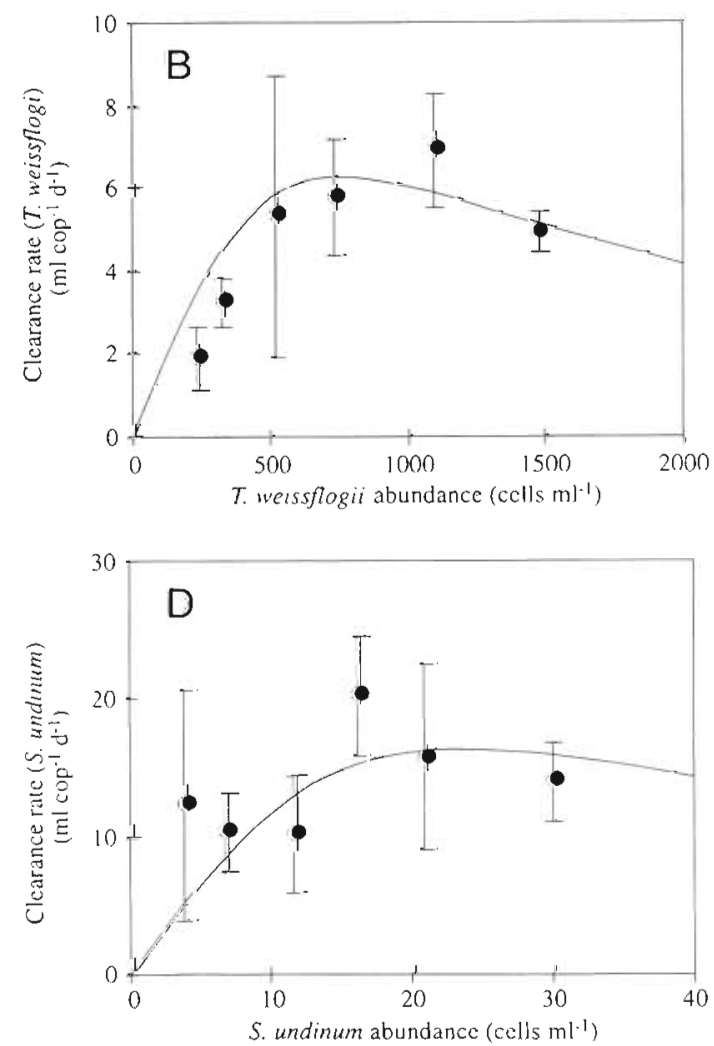

Fig. 2. Acartia clausi ingestion and clearance rates on algae ( $A$ and $B$ respectively) and ciliates ( $C$ and $D$ respectively) as a functions of prey biomass. Solid lines are given by Eqs. (12) \& (13), using the parameters fitted by non-linear least squares (Table 5) 


\section{Copepod functional response $=$ Type 2}
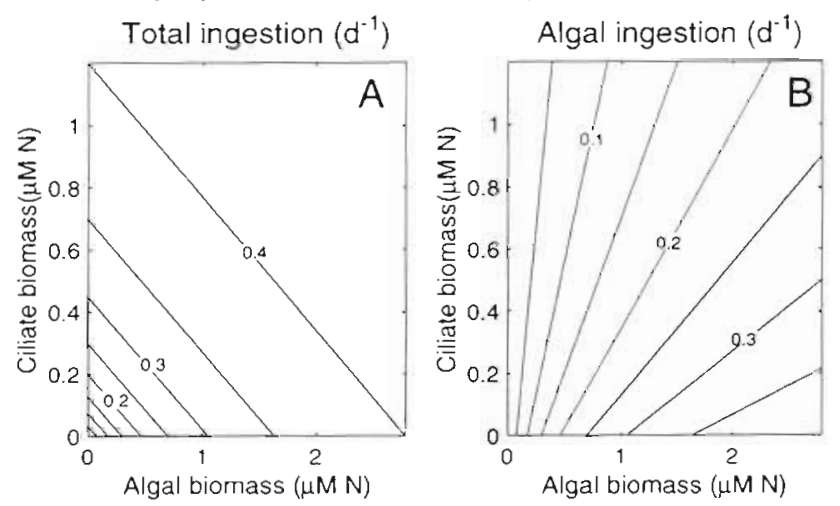

\section{Copepod functional response = Type 3}
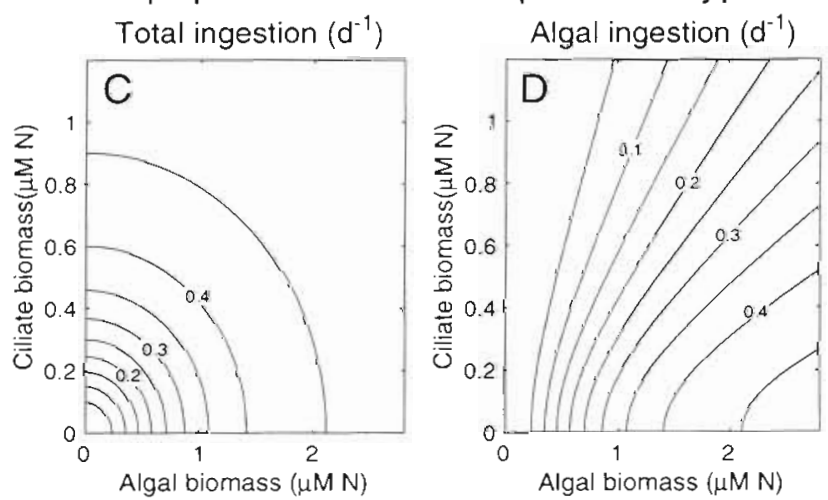

Fig. 3. Acartia clausi. Contour plots of specific ingestion rate as function of algal and ciliate biomass for a copepod having either $(A, B)$ a type 2 or $(C, D)$ a type 3 functional response and parameter values given by Table 3 . (A, C) Total ingestion rate given by Eq. (10); (B, D) algal ingestion rate given by Eq. (12)

type 3 functional response was used (Fig. 3A, C). Above this concentration, copepods with switching behaviour had the highest food intake (Fig. 3A, C). This can also be seen in Fig. 4A, C. While copepods with a type 2 response ingest algae in a fixed proportion to available food, a switching predator concentrates its feeding efforts on the most abundant prey (Fig, 3B, D).

Using Eqs. (12) \& (13) we could investigate the magnitude of $n$ and decide whether our experimental results corresponded to a type 2 or a type 3 functional response. Non-linear regressions were run in order to find the parameter values of $I_{Z,}^{\prime} C_{A, Z}^{\prime}, C_{P, Z,}^{\prime}$ and the switching shape parameter $n$ which fitted best to our experimental data. Best fit was obtained by a sigmoid curve, with a switching shape parameter of $n=2.1$ (Table 5). The corresponding curves for ingestion and clearance rates are shown in Fig. 2. The curve fitted to the data deviated significantly from a Holling type 2 functional response, as the switching shape parameter was significantly different from 1 (Table 5).

The maximum ingestion rate of copepods, $I^{\prime} Z$, was adjusted to a temperature of $20^{\circ} \mathrm{C}$ by a $Q_{10}$ of 2.3 (Durbin \& Durbin 1992) before it was entered into the model. The ingestion curves that were entered into the model are shown in Fig. 4A (type 2 functional response, $\mathrm{n}=1$ ) and Fig. $4 \mathrm{C}$ (type 3 functional response, $n=2$ ). The corresponding curves for copepod net growth rate as a function of algal biomass are compared to ciliate net growth in Fig. 4B, D. The threshold algal concentrations for net growth of ciliates were lower than for copepods irrespective of the type of functional response displayed by the copepods. The threshold for copepods was higher when a type 3 functional response was used compared to a type 2 . Deduction of stationary points with both ciliates and copepods together revealed that ciliates should have a lower threshold algal concentration for positive net growth than copepods in order for both grazers to coexist in this simplified system (Appendix 1). Although such data are scarce, there is evidence that some common pelagic ciliates may have lower thresholds, or at least thresholds of the same magnitude as copepods (Gismervik et al. in press).

Table 5. Parameter estimates and their $95 \%$ confidence limits (in parentheses) for best non-linear fit of Eqs. (12) \& (13) to experimental data. A switching shape parameter of $n=2$ was used in the second run (non-linear fit for 3 parameters)

\begin{tabular}{|c|c|c|c|}
\hline Parameter & Abbreviation & Estimate & $95 \% \mathrm{CL}$ \\
\hline \multicolumn{4}{|c|}{ Non-linear fit for 4 parameters, $\mathrm{di}=32, \mathrm{RMSE}=\mathbf{0 . 0 2 6 1}$} \\
\hline Maximum ingestion rate & $\Gamma_{z}^{\prime}\left(\mathrm{d}^{-\mathrm{L}}\right)$ & 0.23 & $(0.17,0.58)$ \\
\hline Incipient limiting algae concentration & $C_{A . Z}^{\prime}\left(\mu g \mathrm{Cl}^{-1}\right)$ & 52 & $(25,196)$ \\
\hline Incipient limiting ciliate concentration & $C_{p, Z}^{\prime}\left(\mu \mathrm{g} \mathrm{C} \mathrm{J}^{-1}\right)$ & 18 & $(8.72)$ \\
\hline Switching shape parameter & $n$ & 2.1 & $(1.2,3.4)$ \\
\hline \multicolumn{4}{|c|}{ Non-linear fit for 3 parameters, $\mathrm{df}=33, \mathrm{RMSE}=0.0257$} \\
\hline Maximum ingestion rate & $I^{\prime} z\left(\mathrm{~d}^{-1}\right)$ & $0.24^{\circ}$ & $(0.20,0.31)$ \\
\hline Incipient limiting algae concentration & $C_{A, Z}^{\prime}\left(\mu \mathrm{g} \mathrm{Cl}^{-1}\right)$ & 55 & $(32,81)$ \\
\hline Incipient limiting ciliate concentration & $C_{P, Z}^{-1, Z}\left(\mu g \mathrm{Cl}^{-1}\right)$ & 19 & $(11,28)$ \\
\hline
\end{tabular}




\section{Copepod functional response $=$ Type 2}
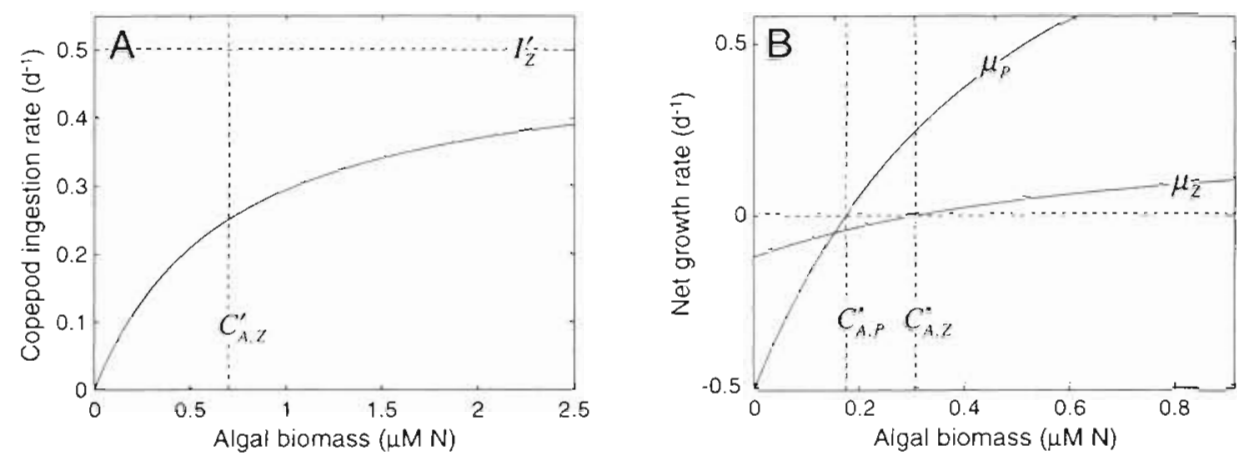

Fig. 4. (A, C) Copepod ingestion rate as function of algal biomass when ciliates are absent [(A) type 2, (C) type 3 functional response]. (B, D) Copepod net growth rate as function of algal biomass when ciliates are absent [(B) type 2 , (D) type 3 functional response]. Ciliate net growth as function of algal biomass when copepods are absent is shown for comparison. Symbols and parameters are defined in Tables 2 \& 3 and in Appendix 1

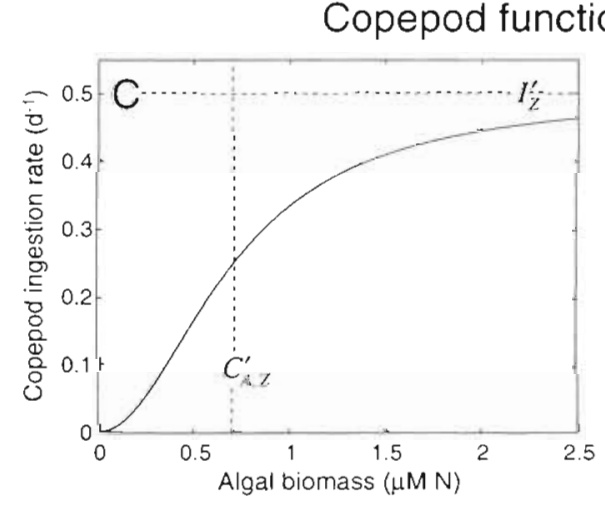

response $=$ Type 3

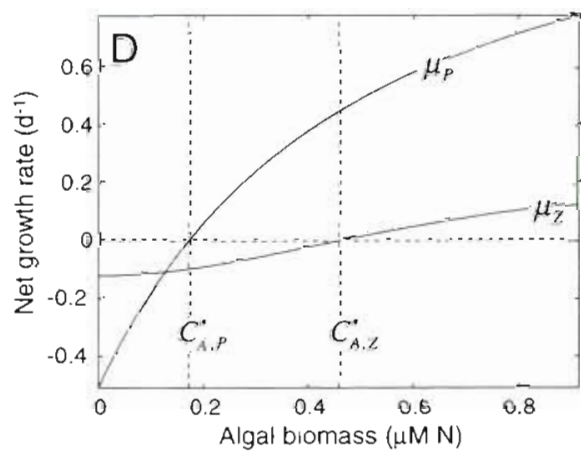

\section{Model analysis}

Bifurcation diagrams (Figs. 5 \& 6) show the location and local stability of the stationary points of a dynamic system as functions of an external parameter. Appendix 1 describes the analysis of the stationary points of the model given by Eqs. (1) to (4) when the external nutrient input concentration $\left(C_{N, \text { in }}\right)$ is taken as the bifurcation parameter. A common feature of all bifurcation diagrams for this kind of systems is that below some low level of nutrient supply neither of the herbivores is able to persist, thus resulting in a degenerate stationary state with algae as the only biotic component. Above this threshold level, bifurcation diagrams for the present model have 3 major branches corresponding to stationary points with biomasses of either ciliates, copepods, or both being non-zero (labeled I, II, and III, respectively, in Figs. 5 \& 6).

Bifurcation analyses were performed on 2 different cases with identical model parameters (as given by Table 3), except for the switching shape parameter $n$, introduced in Eq. (10), which was set either to 1 or 2 (corresponding to copepods having either type 2 or type 3 functional responses). When a type 2 functional response was applied for copepod ingestion, non-zero solutions for both ciliates and copepods were only possible over a very narrow interval at very low input nutrient concentrations (Fig. 5). In this interval the coexistence between ciliates and copepods was also the only locally, asymptotically stable solution. Thus ciliates will in this interval be able to successfully invade a community consisting of only algae and copepods, and vice versa. Increasing nutrient input concentration above this interval leads to the deterministic extinction of the ciliate population, because the ciliates are no longer able to compensate for the increasing predation losses imposed by the copepod population. The coexistence between ciliates and copepods will thus in this case be very fragile with respect to changes in nutrient supply. Copepods are able to maintain a stable equilibrium up to an intermediate level of nutrient supply, above which there are no locally stable solutions. Local stability is lost by a Hopf bifurcation to a limit cycle with alternations between algal blooms and periods of intense overgrazing, as in the classical 'paradox of enrichment' described by Rosenzweig (1971).

In contrast, when a type 3 functional response was applied for copepod ingestion, stable coexistence between ciliates and copepods occurred even at high input nutrient concentrations (Fig. 6). Stability loss occurred instead over a limited range at low nutrient concentrations $(0.5$ to $1.5 \mu \mathrm{M})$. Simulations showed that this stability loss resulted in a limit cycle with 

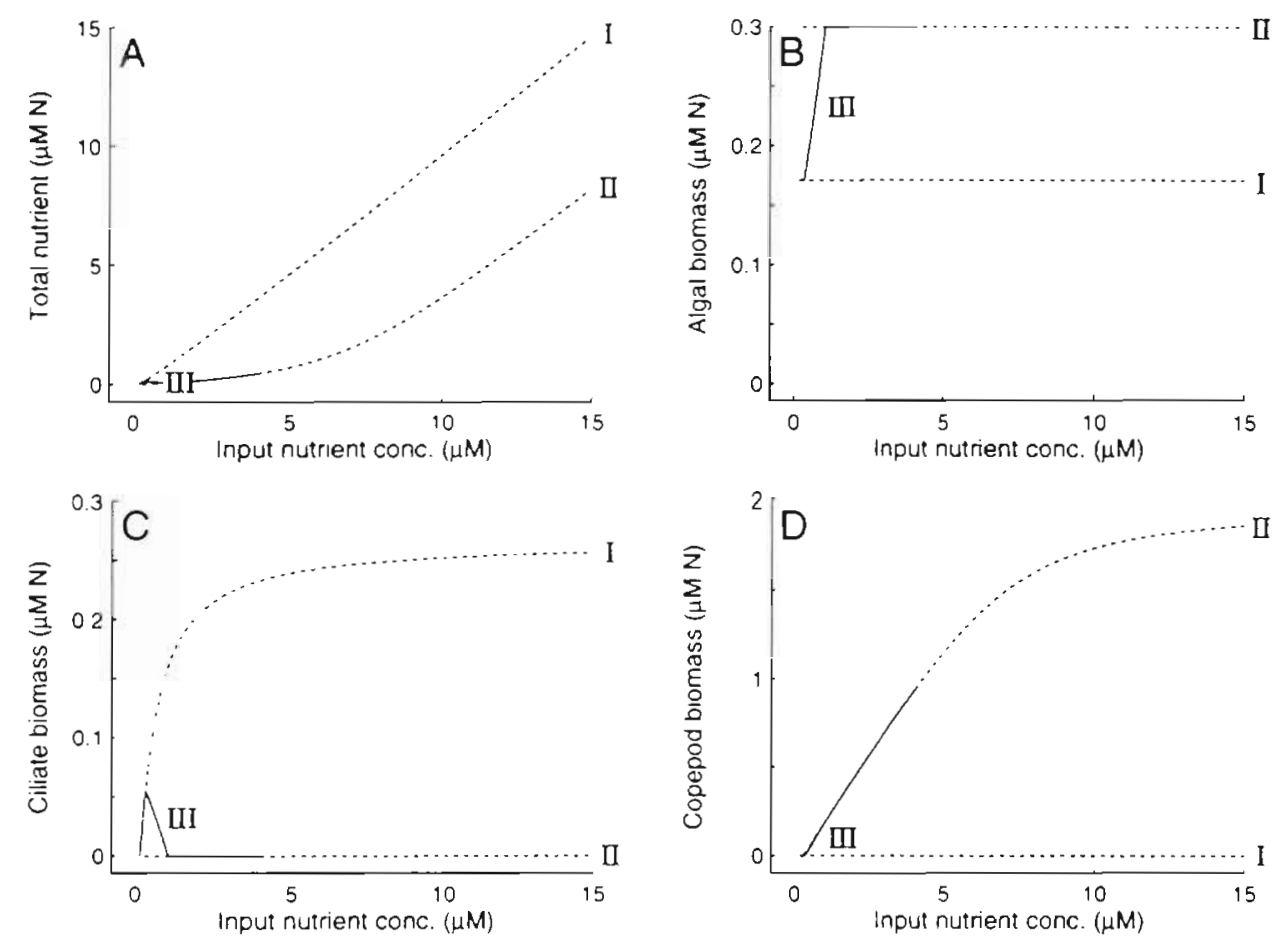

Fig. 5. Bifurcation diagram for the 4-compartment model (Fig. 1) when copepods are assumed to have type 2 response (see Appendix 1 for details on the bifurcation analysis). Branch labels denote stationary states with I: ciliates alone; II: copepods alone, III: both ciliates and copepods present. Dashed lines: unstable stationary states; solid lines: stable stationary states

much less vigorous oscillations than the previous case (oscillation period 10 to $15 \mathrm{~d}$, relative amplitude $<50 \%$ of mean), and that ciliates and copepods were able to coexist in this limit cycle when the nutrient supply was sufficient to support copepod persistence. Above this range, only the solution with both ciliates and copepods was locally stable, meaning that neither predator species will be able to suppress the invasion of the other one. Copepod switching between ciliate and algal food kept the ciliate biomass on a constant level
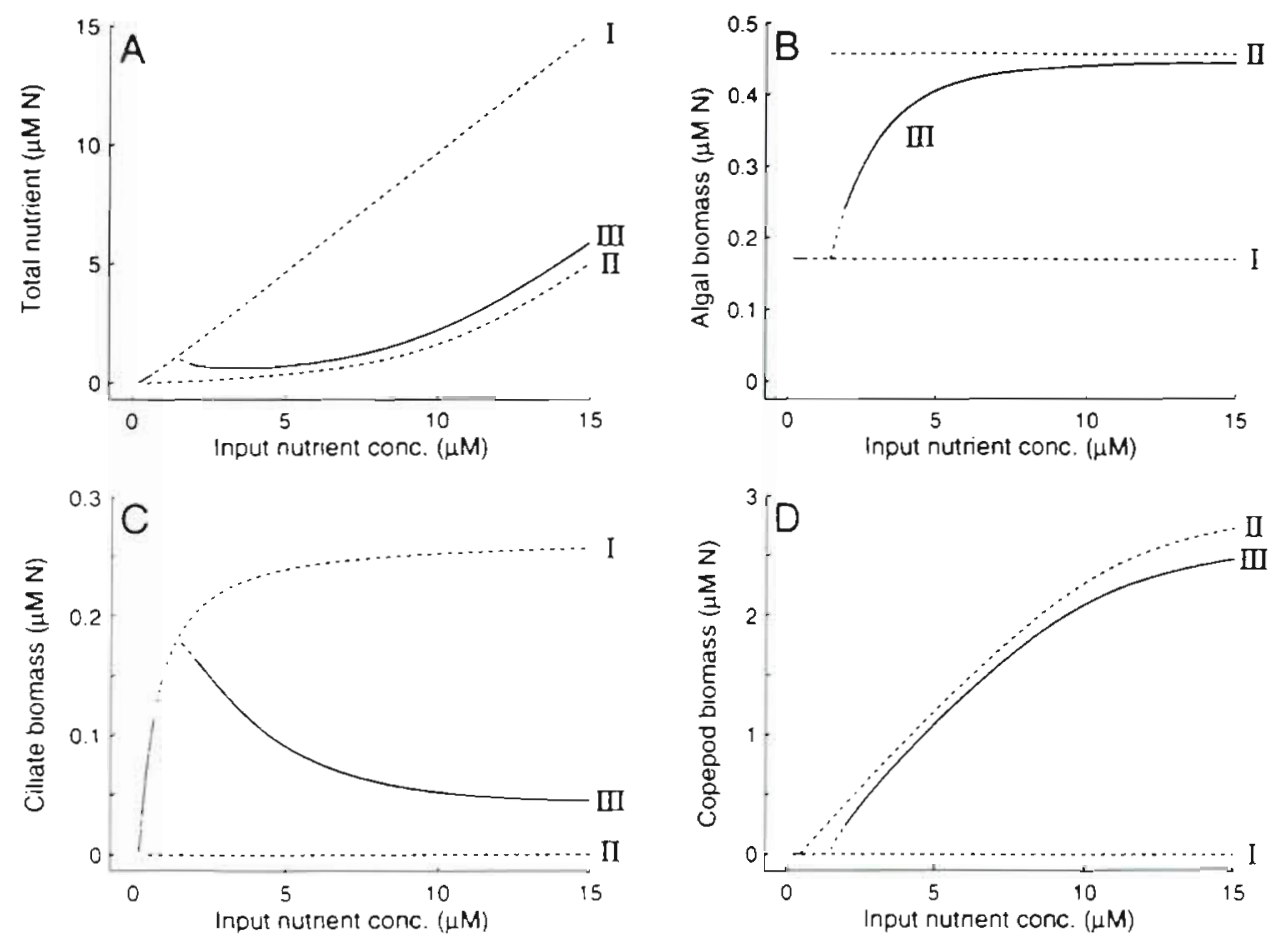

Fig. 6. Bifurcation diagram for the 4-compartment model (Fig. 1) when copepods are assumed to have type 3 response (see Appendix 1 for details on the bifurcation analysis). Branch labels denote stationary states with I: ciliates alone; II: copepods alone; III: both ciliates and copepods present. Dashed lines: unstable stationary states; solid lines: stable stationary states 
and thereby ensured a constant grazing pressure on the algal community. The algal biomass at steady state was then higher than when ciliates acted alone, but lower than when copepods were the only grazers (Fig. 6B). The coexistence of ciliates and copepods was insensitive to changes in nutrient input whenever the nutrient supply rate was sufficient to support the existence of a copepod population.

\section{DISCUSSION}

\section{Experimental results}

Acartia clausi increased its clearance rates with increasing prey concentrations when there was an alternating prey present - both in Expt 1, when the algal biomass was increased, and in Expt 2, when the ciliate biomass was increased. These results are consistent with type 3 functional responses, and are probably due to $A$. clausi switching its feeding effort from algae to ciliates (from suspension feeding to ambush feeding) when ciliate biomass is increased, and vice versa [see Fig. 4 in Marten (1973) for an informative presentation of the feeding upon 2 alternate prey]. There are but a few experiments which reveal a type 3 response in copepods. Jonsson \& Tiselius (1990) found enhanced clearance rates for $A$. tonsa at increasing concentrations of the ciliate Strombidium reticulatum. When both ciliates and the algae Cryptomonas baltica were present, the copepods doubled their time devoted to suspension feeding behaviour when the biomass of the algae was increased from 330 to $1100 \mu \mathrm{g}$ $\mathrm{C}^{-1}$. A similar result was obtained by Kiørboe et al. (1996). They also showed that the clearance rate of algae Thalassiosira weissflogii by the copepod $A$. tonsa depended on the availability of ciliate prey. However, in their study, the clearance rate of ciliates was almost constant independent of the biomass of algae. The authors argued that this discrepancy could be related to the fact that this particular ciliate species was not able to escape the feeding current of $A$. tonsa. Thus the copepod might have been able to clear ciliates also in the suspension feeding mode (Kiorboe et al. 1996)

The clearance rates obtained for Acartia clausi in our study were low. This may partly be due to low activity of the animals during winter (they were collected at a surface temperature of $5^{\circ} \mathrm{C}$, and acclimated to an experimental temperature of $11^{\circ} \mathrm{C}$ ). It can also indicate that our estimates of radioactivity per food cell (ciliates and algae) were overestimated. A biased estimate of the activity per food item should, however, not interfere with the type of functional response obtained.
There is scattered evidence that the large Calanus spp. may switch between prey types. C. pacificus increased its clearance rates when available nauplii carbon increased compared to algal carbon (Landry 1981). C. helgolandicus fed disproportionately on large Ditylum cells (Richman \& Rogers 1969), and recently, Nejstgaard et al. (1997) found that preference for Emiliania huxleyi by $C$. finmarchicus increased as the abundance of E. huxleyi increased. This could be interpreted as switching behaviour. Some freshwater copepods and daphnids may also display type 3 feeding responses (Chow-Fraser \& Sprules 1992, Wickham 1995).

There is also evidence that some copepods display type 3 functional responses in 1 prey situations. Acartia spp. tend to reduce their clearance rates for algae below some threshold food abundance (Deason 1980, Kiørboe et al. 1985, Paffenhöfer \& Stearns 1988, Durbin \& Durbin 1992, Kiørboe et al. 1996). For diatoms, the clearance rate decreases when the abundance is below $\sim 100$ to 500 cells $\mathrm{ml}^{-1}$, or $\sim 4$ to $40 \mu \mathrm{g}$ $\mathrm{C}^{-1}$. For smaller flagellates the level where clearance rate starts to decrease seems to be higher (Kiørboe et al. 1985: maximum clearance rate at $150 \mu \mathrm{g} \mathrm{C} \mathrm{l^{-1 }}$ for Rhodomonas baltica; Gismervik unpubl. results: maximum clearance rate at about 5000 cells $\mathrm{ml}^{-1}$ for Tetraselmis damir). According to Paffenhöfer \& Stearns (1988) the decrease in clearance rate in $A$. tonsa at low algal food concentrations may be due to few chemoreceptors, and an inability to change the flow field in order to re-route cells that are displaced towards the copepod. Thus, this initial increase in clearance rates for algae found by some investigators is generated by switching from non-feeding to feeding activities (Marten 1973). A feeding threshold may also exist for other copepods, like Calanus spp. (Parsons et al. 1969, Frost 1975).

Copepod feeding threshold for ciliates is considerably lower than for algae $10.3 \mu \mathrm{g} \mathrm{C} \mathrm{l}^{-1}$ for Acartia tonsa feeding on Strombidium reticulatum), and maximum clearance rate is achieved at low concentrations (Jonsson \& Tiselius 1990). A tonsa's ability to feed at high rates at such low concentrations of ciliates may be due to specialization for carnivory by numerous mechanoreceptors on the first antenna (Paffenhöfer \& Stearns 1988, Jonsson \& Tiselius 1990). Prey moving in the vicinity of the copepod will be detected and captured.

\section{Model results: predictions}

The experiments were designed to reveal functional responses in copepods when presented with 2 prey types, 1 motile and 1 non-motile. We chose Thalas- 
siosira weissflogii as this alga has been frequently used in feeding experiments with copepods, because it is too large to be eaten by the ciliate, and to reduce the effects of size between the motile and non-motile prey. However, in the model we wanted to explore interactions between copepods and ciliates feeding on the same prey, while at the same time they were engaged in a predator-prey relationship. This blend of competition and predation has been termed intraguild predation by Polis \& Holt (1992). Intraguild predation theory (see Polis \& Holt 1992) has predicted several effects of predation in a 4 component system as shown in Fig. 1: coexistence between the predators (copepods) and the consumers (ciliates) is promoted, given that the consumers (ciliates) are the superior competitors for the shared prey (algae), and predation can indirectly increase prey abundance (algae biomass) by depressing the most efficient consumers (ciliates). Both effects are demonstrated by our model, however, a switching response of the predator is an additional prerequisite for coexistence over an extended range of nutrient supply (Figs. 5 \& 6). When copepods are present, ciliate biomasses are maintained at low stable levels, and consequently the algal biomasses are higher and more stable than when ciliates act alone (Fig. 6B, C). Several field studies support the theory of predation control of ciliates, except during periods of low copepod abundance, e.g. spring (Smetacek 1981, Kivi et al. 1993, Nielsen \& Kiørboe 1994).

A strength of our experiments and model is that they encompass realistic abundances. The experiments indicate that copepods switch towards ciliates when biomasses pass $14 \mu \mathrm{g} \mathrm{C} \mathrm{l}^{-1}(\sim 13$ small ciliates $\mathrm{ml}^{-1}$ ), and the model simulations indicate stable ciliate biomasses between 1 and $10 \mathrm{ml}^{-1}$. This is in accordance with observed abundances/biomasses of ciliates in coastal waters, although maximum values may be higher (Stoecker et al. 1989, Leakey et al. 1993. Nielsen \& Kiørboe 1994, Edwards \& Burkill 1995, Gismervik 1997b). Furthermore, it may partly explain the high diversity of ciliate species with seemingly identical trophic position in plankton samples, as one species will be hindered in monopolizing resources. When discussing the paradox of the plankton, Hutchinson (1961) suggested that predation could promote coexistence of prey species. Indeed, the recognition of the omnivore habits of marine crustaceans as well as discovery of numerous mixo- and heterotrophic protists further suggests that predation may be important in structuring plankton communities.

Our model is a simplified system, investigating the impact of different functional response of copepods on food web stability. While we have investigated func- tional responses in the copepod Acartia clausi, we have no data to verify the outcome of the model. Copepods in our model feed on both ciliates and algae, while they simultaneously compete with ciliates for food (intraguild predation). Thus, net phytoplankton have been excluded from our model. In natural systems, increased nutrient input will generally lead to an increase in the biomass of net phytoplankton, while less changes appear in the microbial food web (Nielsen \& Kiørboe 1991, Kiørboe 1993, Riegman et al. 1993). Hence, increased nutrient input will tend to increase the importance of the traditional food web, or overflow system, compared to the maintenance system, in the terminology of Riegman et al. (1993). Our model results partly explain how the microbial food web may stay basically the same through density dependent selectivity of ciliates by copepods, which allow the remaining ciliate community to keep up a constant grazing pressure on the nanoplankton. Our model does not include the heterotrophic part of the microbial community (DOM-bacteria-heterotrophic flagellates), thus caution should be exercised when extrapolating our results to natural systems. In contrast to the smaller plankton (both auto- and heterotrophic), net plankton escapes grazing from most protozoans, and the grazing pressure from copepods is generally too low to control net phytoplankton blooms (Kiørboe 1993). As our model does not include net phytoplankton, we may not predict the outcome of increased nutrient input to a natural system. Nevertheless, due to the high selectivity of ciliates over algae, we would expect switching copepods to control ciliate abundances even when net phytoplankton is included. Thus, the increased nutrient concentrations should be channeled to net phytoplankton, and not smaller phytoplankton which is controlled by grazers, as predicted by e.g. Riegman et al. (1993).

In this study we have empirically investigated the functional response of a switching copepod, and by applying a simple model we have strengthened our notion of copepods as important structuring components of the pelagic food web. Switching copepods are potential key species that should be given special attention in future studies.

Acknowledgements. We thank Wenche Eikrem and Peter Tiselius for providing the algae (Nephroselmis pyriformis and Thalassiosira weissflogii respectively), and David J. S. Montagnes for help with the protargol stain of ciliates. We are also grateful to Per J. Færøvig for analysing the $\mathrm{C}$ and $\mathrm{N}$ content of the ciliates and algae, and to Stein Kaartvedt for critically reading the manuscript. This study forms a part of the research programme on marine pollution (PMF) financed by the Norwegian Research Council (NFR), and was also supported by the programme on marine resources and environments (MAREMT). 
Appendix 1. Stationary points and local stability analysis

Stationary points are defined by the non-linear equation system resulting from setting the time derivatives (i.e. left hand sides) of Eqs. (1) to (4) equal to zero. In general, such a system of non-linear equations may have zero, 1 , or many solutions which may be locally stable or not, depending on the signs of eigenvalues of the Jacobian matrix corresponding to a given stationary point. A bifurcation analysis deals with how the location and local stability of stationary points change in response to an external parameter. For the system Eqs. (1) to (4), the most obvious choice of bifurcation parameter is the input nutrient concentration $C_{N, m}$ which determines the nutrient supply rate to the system. Inspection of the system Eqs. (1) to (4) reveals that it must have several non-persistent solutions corresponding to 1 or more of the state variables being zero. Both the trivial solutions when both predators are extinct $\left(C_{p}{ }_{p}=C^{\prime} z=0\right.$, where $C^{\cdot}$ denotes the value of state variable $C$ at a stationary point), and solutions where only 1 of the consumers (either ciliates or copepods) has non-zero abundance are important branches of the bifurcation diagram. Some of these non-persistent solutions will be investigated first:

Stationary points with ciliates alone. When copepods are absent $\left(C^{\circ} z=0\right)$, Eq. (3) implies that ciliate growth rate must be exactly balanced by dilution/advection losses $(D)$, which again means that algal biomass must be equal to the threshold concentration for positive net growth for ciliates:

$$
C_{A, P}^{\cdot}=\frac{r_{P}+D}{\varepsilon_{P} I_{P}^{\prime}-\left(r_{P}+D\right)} C_{A, P}^{\prime}
$$

From here, one might go on and solve the steady state Eqs. (1) \& (2) for $C_{p}{ }_{p}$ and $C_{N}{ }_{N}$ as functions of $C_{N i n}$ by brute force. This approach leads to a quadratic equation where only 1 solution is feasible in the sense that it corresponds to an inorganic nutrient concentration $C^{\cdot}>0$. Alternatively, one might find the feasible solution directly by taking an approach employed by Andersen (1997), where one chooses an arbitrary algal growth rate $\mu_{A}{ }_{A}$, such that $D \leq \mu_{A}{ }_{A}<\mu^{\prime}{ }_{4}$. Given $\mu_{A,}^{*} C_{A, P}^{*}$ and $I_{P}^{*}$ [from substituting $C_{A, P}^{*}$ into Eq $\{9\}$ ]. we can solve Eq. (2) for the ciliate biomass:

$$
C_{p}^{*}=\frac{\mu_{A}^{*}-D}{I_{p}} C \cdot{ }_{A, P}
$$

Given $\mu$; we can also solve the Monod equation (Eq. 6) for the corresponding inorganic nutrient concentration $C{ }_{N}$. Finally, from substituting $I_{P}^{*}, \mu_{p}^{*}$ and $C_{p}^{*}$ into Eq. (5) to yield the regeneration rate $R^{\circ}{ }_{N}$, we can solve Eq. (1) for our bifurcation parameter, the input nutrient concentration $C_{N, i n}$ :

$$
C_{\lambda, i n}=D^{-1}\left(\mu_{4} C_{*}-R_{*}^{*}\right)+C_{N}
$$

Repeating this procedure for different values of $\mu_{4}$ yields stationary state vectors $\left(C \cdot C_{N}, p, C_{p}^{*}, 0\right)$ as function of $C_{N, n}$, which can be used to construct the branches of the bifurcation diagram that corsespond to ciliates alone.

Stationary points with copepods alone. In analogy with the previous case, the steady state mass balance Eq. (4) implies that copepod growth rate must be exactly balanced by dilution/advection $(D)$ and mortality $\left(m_{z}\right)$ losses, which again means that algal biomass must be equal to the threshold concentration for positive net growth for copepods:

$$
C \cdot \cdot_{A, Z}=\left(\frac{r_{Z}+m_{Z}+D}{\varepsilon_{Z} l_{Z}^{\prime}-\left(r_{Z}+m_{Z}+D\right)}\right)^{\frac{1}{7}} C_{A, Z}^{\prime}
$$

If we proceed as in the previous case, we can for a given $D \leq \mu_{A}^{*}<\mu_{A}^{\prime}$ solve the Monod equation (Eq. 6) for $C^{\circ}$. Furthermore, we can in analogy with Eqs. (A2) \& (A3) solve Eqs. (2) \& (1) for $C_{z} z$ and $C_{N, I n}$, respectively. Repeating this procedure for different values of $\mu_{A}^{*}$ yields stationary state vectors $\left(C_{N}^{*}, C_{A, Z}^{*}, 0, C_{z}^{*}\right)$ as functions of $C_{N, m}$, which can be used to construct the branches of the bifurcation diagram that correspond to copepods alone.

Stationary points with ciliates and copepods together. For the persistent system (i.e. for which all state variables are positive), Eq. (4) must still be valid, as in the previous case, but now subject to the condition that copepod consumption of algae and ciliates together is sufficient to balance losses. In other words, steady state concentrations of algae and ciliates $\left(C_{4}^{*}\right.$ and $\left.C_{p}^{*}\right)$ must be such that the combined consumption rate of both prey is the same as on algae alone at concentration $C^{*}, z$ :

$$
\left(\frac{C_{A}^{*}}{C_{A, Z}^{i}}\right)^{n}+\left(\frac{C_{p}^{\cdot}}{C_{P, Z}^{i}}\right)^{n}=\left(\frac{C_{A, Z}^{*}}{C_{A, Z}^{i}}\right)^{n}
$$

This requirement implies that all stationary points with ciliates and copepods present must be such that $C_{A}<C_{A, 2}$. Furthermore, we must also require that the algal concentration is higher than what is necessary for ciliates to exist in the absence of copepods if they are going to persist when suffering additional losses due to copepod predation; that is, $C_{A}>C_{A, p}$. The constraint $C_{A, P}<C_{A}^{*}<C_{A, z}$ means that coexistence of ciliates and copepods in the system described here is only possible when the community composition rule $C_{A, P}<C_{A, Z}$ is satisfied, i.e. when ciliates are superior to copepods in pure competition for algal prey.

Computation of stationary points can be performed as above, but this time starting out from an arbitrary algal biomass $C_{A, P}^{*}<C_{A}^{*}<C_{A, Z}^{*}$. With $C_{A}^{*}$ given, we can solve Eq. (A.5) for $C_{p}{ }_{p}$. We can also compute $\mu_{p}^{\circ}$ by substituting $C_{A}{ }_{A}$ into Eqs. (7) \& (9), and $I_{P Z}$ by substituting $C^{*}$ and $C^{*}{ }_{P}$ into Eq. (13) - which again means that we can solve Eq. (3) for $C_{z}$

$$
C_{z}=\frac{\mu_{p}^{*}-D}{I_{P, z}^{*}} C_{p}^{*}
$$

Having solved for $C_{A}^{*}, C_{p}^{*}$, and $C_{Z}^{*}$, we can solve Eq. (2) for $\mu_{A}^{*}$ lafter computing $I_{p}^{*}$ and $I_{A, Z}^{*}$ from Eqs. (7) \& (12)]:

$$
\mu_{\dot{A}}=D+\frac{I_{p} C_{p}^{*}+I_{A, Z} C_{Z}^{*}}{C_{A}}
$$

From $\mu_{A}$ we can solve the Monod equation (Eq. 6) for $C_{{ }_{N}}$, and, finally, solve Eq. (1) for $C_{N, n}$ as in Eq. (A3). Repeating this procedure for different values of $C_{A}$; yields stationary points $\left(C{ }_{N}, C_{A, Z}, C_{p}^{*}, C_{Z}^{*}\right.$ ) as functions of $C_{N, m}$, which can be used to construct the branches of the bifurcation diagram that correspond to coexistence between ciliates and copepods.

Local stability analysis. Analytical local stability analysis of the 4-dimensional system studied here could in principle have been performed by extracting the Routh-Hurwitz determinants of the 4 th order characteristic polynomial of the Jacobian, as described in standard textbooks on dynamic systems (e.g. Luenberger 1979). As this procedure yields some very unwieldy and rather uninformative expressions for the present system, we have instead chosen a numerical approach. Analytical expressions for the elements of the Jacobian matrix of the system are found by taking partial derivatives of the right hand sides of Eqs. (1) to (4) with respect to the state variables. For a given set of parameters and a given stationary state vector $\left(C^{*}, C_{i}^{*}, z\right.$ $C_{p}{ }_{p}, C_{z} z$ ), the eigenvalues of the Jacobian matrix can thus be found numerically by standard methods (such as the eig function in MATLAB). This means that all stationary points can be classified as stable or not depending on the eigenvalues of the Jacobian matrix at that particular point (all eigenvalues having negative real parts implies local stability), such that the bifurcation diagram can be divided into stable and unstable branches as shown in Figs. $5 \& 6$. 


\section{LITERATURE CITED}

Andersen T (1997) Pelagic nutrient cycles. Herbivores as sources and sinks. Ecological studies 129. Springer Verlag, Berlin

Carlotti F, Nival S (1992) Moulting and mortality rates of copepods related to age within stage: experimental results. Mar Ecol Prog Ser 84:235-243

Chow-Fraser P: Sprules WG (1992) Type-3 functional response in limnetic suspension-feeders, as demonstrated by in situ grazing rates. Hydrobiologia 232:175-191

Crawford DW, Stoecker DK (1996) Carbon content, dark respiration and mortality of the mixotrophic planktonic ciliate Strombidium capitatum. Mar Biol 126:415-422

Deason EE (1980) Grazing of Acartia hudsonica (A. clausi) on Skeletonema costatum in Narragansett Bay (USA): influence of food concentration and temperature. Mar Biol 60: $101-113$

Durbin EG, Durbin AG (1992) Effects of temperature and food abundance on grazing and short-term weight change in the marine copepod Acartia hudsonica. Limnol Oceanogr 37:361-378

Edwards ES, Burkill PH (1995) Abundance, biomass and distribution of microzooplankton in the Irish Sea. J Plankton Res 17:771-782

Eppley RW, Rogers JN, McCarthy JJ (1969) Half-saturation constants for uptake of nitrate and ammonium by marine phytoplankton. Limnol Oceanogr 14:912-920

Frost BW (1975) A threshold feeding behaviour in Calanus pacificus. Limnol Oceanogr 20:263-266

Gauld DT (1966) The swimming and feeding of planktonic copepods. In: Barnes $H$ (ed) Some contemporary studies in marine science. George Allen \& Unwin, London, p 313-334

Gismervik I (1997a) Stoichiometry of some marine planktonic crustaceans. J Plankton Res 19:279-285

Gismervik I (1997b) Implications of zooplankton stoichiometry on distribution of $\mathrm{N}$ and $\mathrm{P}$ among planktonic size fractions. J Plankton Res 19:343-356

Gismervik I, Andersen T, Vadstein O (1997) Pelagic food webs and eutrophication of coastal waters: impact of grazers on algal communities. Mar Pollut Bull 33:22-35

Green $\mathrm{CH}$ (1988) Foraging tactics and prey selection patterns of omnivorous and carnivorous calanoid copepods. Hydrobiologia 167/168:295-302

Holling CS (1959) The components of predation as revealed by a study of small mammal predation of European pine sawfly. Can Ent 91:293-332

Hutchinson GE (1961) The paradox of the plankton. Am Nat 15:137-145

Jonsson PR (1986) Particle size selection, feeding rates and growth dynamics of marine planktonic oligotrichous ciliates (Ciliophora: Oligotrichina). Mar Ecol Prog Ser 33:265-277

Jonsson PR, Tiselius P (1990) Feeding behaviour, prey detection and capture efficiency of the copepod Acartia tonsa feeding on planktonic ciliates. Mar Ecol Prog Ser 60:35-44

Kiørboe T (1993) Turbulence, phytoplankton cell size, and the structure of the pelagic food webs. Adv Mar Biol 29:1-72

Kiørboe T, Møhlenberg F, Hamburger K (1985) Bioenergetics of the planktonic copepod Acartia tonsa: relation between feeding, egg production and respiration, and composition of specific dynamic action. Mar Ecol Prog Ser 26:85-97

Kiørboe T, Saiz E, Viitasalo M (1996) Prey switching behaviour in the planktonic copepod Acartia tonsa. Mar Ecol Prog Ser 143:65-75

Kivi K, Kaitala S, Kuosa $H_{1}$ Kuparinen J, Leskinen E, Lignell R, Marcussen B, Tamminen T (1993) Nutrient limitation and grazing control of the Baltic plankton community during annual succession. Limnol Oceanogr 38:893-905

Kleppel GS (1993) On the diets of calanoid copepods. Mar Ecol Prog Ser 99:183-195

Koehl MAR (1984) Mechanisms of particle capture by copepods at low Reynolds numbers: possible modes of selective feeding. In: Meyers DG, Strickler JR (eds) Trophic interactions within aquatic ecosystems. AAAS Selected Symposium. Westview Press Inc, Boulder, p 7-27

Landry MR (1981) Switching between herbivory and carnivory by the planktonic marine copepod Calanus pacificus. Mar Biol 65:77-82

Landry MR, Fagerness VL (1988) Behavioural and morphological influences on predatory interactions among marine copepods. Bull Mar Sci 43:509-529

Leakey RJG, Burkill PH, Sleigh MA (1993) Planktonic ciliates in Southampton Water: quantitative taxonomic studies. J Mar Biol Assoc UK 73:579-594

Lehman JT (1976) The filter feeder as an optimal forager, and the predicted shapes of feeding curves. Limnol Oceanogr 21:501-516

Leon JA, Thumpson DB (1975) Competition between two species for two complementary or substitutable resources. J Theor Biol 50:185-201

Lowndes AG (1935) The swimming and feeding of certain calanoid copepods. Proc Zool Soc Lond 22:687-715

Luenberger DG (1979) Introduction to dynamic systems. Theory, models \& applications. J Wiley \& Sons, New York

Marten GG (1973) An optimization equation for predation. Ecology 54:92-101

Martin AJ, Montagnes DJS (1993) Winter ciliates in a British Columbian fjord: six new species and an analysis of ciliate putative prey. J Eukaryot Microbiol 40:535-549

Matsuda H, Kawasaki K, Shigesada N, Teramoto E, Riccardi LM (1986) Switching effect on stability of the prey-predator system with three trophic levels. J Theor Biol 122:251-262

Montagnes DJS (1993) A quantitative protargol stain (QPS) for ciliates and other protists. In: Kemp PF, Sherr BF, Sherr $E B$, Cole JJ (eds) Handbook of methods in aquatic microbial ecology. Lewis Publishers, Boca Raton, p 229-240

Mullin MM, Stewart EF, Fuglister FJ (1975) Ingestion by planktonic grazers as a function of concentration of food. Limnol Oceanogr 20:259-262

Murdoch WW (1969) Switching in general predators: experiments on predator specificity and stability of prey populations. Ecol Monogr 39:335-354

Murdoch WW, Oaten A (1975) Predation and population stability. Adv Ecol Res 9:1-131

Nejstgaard JC, Gismervik I, Solberg P (1997) Feeding and reproduction by Calanus finmarchicus, and microzooplankton grazing during blooms of diatoms and the coccolithophore Emiliania huxleyi. Mar Ecol Prog Ser 147: $197-217$

Nielsen TG, Kiørboe T (1991) Effects of a storm event on the structure of the pelagic food web with special emphasis on planktonic ciliates. J Plankton Res 13:35-51

Nielsen TG, Kiørboe T (1994) Regulation of zooplankton biomass and production in a temperate, coastal ecosystem, 2. Ciliates. Limnol Oceanogr 39:508-519

Oaten A, Murdoch WW (1975) Switching, functional response, and stability in predator-prey systems. Am Nat 109: $299-318$

Paffenhöfer GA, Stearns DE (1988) Why is Acartia tonsa (Copepoda: Calanoida) restricted to nearshore environments? Mar Ecol Prog Ser 42:33-38

Parsons TR, LeBrasseur RJ, Fulton JD, Kennedy OD (1969) Production studies in the Strait of Georgla. Part II. Sec- 
ondary production under the Fraser river plume, February to May 1967. J Exp Mar Biol Ecol 3:39-50

Polis GA, Holt RD (1992) Intraguild predation: the dynamics of complex trophic interactions. Trends Ecol Evol 7:151-154

Poulet SA (1978) Comparison between five coexisting species of marine copepods feeding on naturally occurring particulate matter. Limnol Oceanogr 23:1126-1143

Richman S, Heinle DR, Huff R (1977) Grazing by adult estuarine calanoid copepods of the Cheasapeake Bay. Mar Biol 42:69-84

Richman S, Rogers JN (1969) Feeding of Calanus helgolandicus on synchronously growing populations of the marine diatom Ditylum brightwellii. Limnol Oceanogr 14:701-709

Riegman R, Kuipers B, Noordeloos AAM, Witte HJ (1993) Size-differential control of phytoplankton and the structure of plankton communities. Neth J Sea Res 31:255-265

Rosenzweig ML (1971) Paradox of enrichment: destabilization of exploitation ecosystems in ecological time. Science 171: $385-387$

Royama T (1970) Factors governing the hunting behaviour and selection of food by the great tit. J Anim Ecol 39: $619-668$

Sanders RW, Wickham SA (1993) Planktonic protozoa and metazoa: predation, food quality and population control. Mar Microb Food Webs 7:197-223

Schnack $S$ (1982) The structure of the mouth parts of copepods in Kiel Bay. Meeresforsch 29:89-101

Scott JM (1985) The feeding rates and efficiencies of a marine ciliate Strombidiurn sp., grown under chemostat steady state conditions. J Exp Mar Biol Ecol 90:81-95

Smetacek $V(1981)$ The annual cycle of protozooplankton in the Kiel Bight. Mar Biol 63:1-11

Editorial responsibility: Otto Kinne,

Oldendorf/Luhe, Germany
Steele JH (1974) The structure of marine ecosystems. Harvard University Press, Cambridge, MA

Stevens DW, Krebs JR (1986) Foraging theory. Monographs in behaviour and ecology. Princeton University Press, Princeton, NJ

Stoecker DK (1984) Particle production by planktonic ciliates Limnol Oceanogr 29:930-940

Stoecker DK, Capuzzo JM (1990) Predation on Protozoa: its importance to zooplankton. J Plankton Res 12:891-908

Stoecker DK, Egloff DA (1987) Predation by Acartia tonsa on planktonic ciliates and rotifers. J Exp Mar Biol Ecol 110 $53-68$

Stoecker DK, Sanders NK (1985) Differential grazing by Acartia tonsa on a dinoflagellate and a tintinnid. J Plankton Res $7: 85-100$

Stoecker DK, Taniguchi A, Michaels AE (1989) Abundance of autotrophic, mixotrophic and heterotrophic planktonic ciliates in shelf and slope waters. Mar Ecol Prog Ser 50:241-254

Tinbergen L (1960) The dynamics of insect and bird predation in pine woods. Arch Neerl Zool 13:259-472

Tiselius P, Jonsson PR (1990) Foraging behaviour of six calanoid copepods: observations and hydrodynamic analysis Mar Ecol Prog Ser 66:23-33

Vanderploeg HA, Scavia D, Liebig JR (1984) Feeding rate of Diaptomus sicilis and its relation to selectivity and effective food concentration in algal mixtures and in Lake Michigan. J Plankton Res 6:919-941

Wickham SA (1995) Cyclops predation on ciliates: species specific differences and functional responses. J Plankton Res 17:1633-1646

Wilson DS (1973) Food size selection among copepods. Ecology $54: 909-914$

Submitted: January 27, 1997; Accepted: July 14, 1997

Proofs received from author(s): September 19, 1997 